\title{
Giant Sialolith of Submandibular Duct
}

\author{
Pirabu Sakthivel, ${ }^{1}$ Rijendra Yogal, ${ }^{1}$ Sanjoy Singh, ${ }^{1}$ Prateek Sharma, ${ }^{1}$ Chirom Amit Singh ${ }^{1}$ \\ ${ }^{1}$ Department of ENT, All India Institute of Medical Sciences, New Delhi, India.
}

\section{ABSTRACT}

Sialolithiasis is one of the most common diseases of salivary glands and commonly involves submandibular gland and ducts. "Giant sialoliths" typically measure more than $15 \mathrm{~mm}$ in any dimension. Here, an unusual case of sialolith in submandibular duct is reported which progressed into a giant sialolith in six months' time is reported. A 42-year-old man presented with complaints of recurrent pain and swelling in the right submandibular area. A large stone was palpable intraorally within the Wharton's duct and intra-operatively, an elongated giant sialolith of $50 \mathrm{~mm}$ length was found which is the second largest to be published till date.

Keywords: Giant Sialoliths; Wharton's duct; Sialolithiasis.

\section{INTRODUCTION}

Sialolithiasis is one of the most common diseases of salivary glands. Obstructing the salivary flow either in major and minor salivary glands or in the ducts of these glands, sialoliths cause swelling, pain and recurrent infections of the associated gland. Its incidence is around $1.2 \%$ in adult population and is more prevalent in middle aged men., ${ }^{1,2}$ More than $80 \%$ of sialoliths occur in the submandibular gland or its duct, 5-7\% in the parotid and $1-3 \%$ in the sublingual gland or minor salivary glands. ${ }^{3-5}$ The stones are typically composed of calcium phosphate or calcium carbonate in association with other salts and organic material such as glycoproteins, desquamated cellular residue, and mucopolysaccharides. Ductal stones are elongated in shape whereas hilar stones tend to be oval. ${ }^{6}$

Various factors favour stone formation in submandibular duct and glands, namely highly viscous alkaline saliva, higher mucin and calcium contents, and Wharton's duct being longer and tortuous, running against gravity with a slower salivary flow. ${ }^{7}$ Simultaneous lithiasis in more than one salivary gland is rare, occurring in fewer than $3 \%$ of cases. Also, 70 to $80 \%$ of cases feature solitary stones; only about $5 \%$ of patients have three or more stones. $^{4}$

Eventhough most submandibular calculi are radio- opaque, approximately $20 \%$ are radiolucent, and sialography or sialendoscopy may be required to diagnose them. ${ }^{8}$ The largest reported sialolith previously was $6-\mathrm{cm}$ in length and had a dry weight of 50 grams. $^{7}$ A rare case of giant sialolith of submandibular duct measuring $50 \mathrm{~mm}$ in length was removed intraorally and is reported here with relevant literature. To the best of our knowledge, this is the second largest giant sialolith reported till date.

\section{CASE REPORT}

A 45-year-old male patient presented to our outpatient department with the complaints of recurrent pain and swelling in the right submandibular region for 6 months especially during meals. Intra-oral bimanual palpation revealed a hard stone in the right submandibular duct, approximately $15 \times 10 \mathrm{~mm}$ in size. The orifice of Wharton's duct was swollen, and the floor of the mouth was minimally elevated on right side. A preliminary diagnosis of right submandibular ductal sialolithiasis was made and an ultrasound examination was performed which revealed a calcified mass of $25 \times 10$

Correspondence: Dr. Rijendra Yogal, Department of ENT, All India Institute of Medical Sciences, New Delhi, India. Email: rijendrayogal@gmail.com, Phone+91-9654901965. 
$\mathrm{mm}$ size in the right submandibular duct (Figure 1). The patient was advised for intraoral removal of stone but he refused for surgery initially. He presented again after six months with increasing pain and swelling, and underwent intra-oral removal of stone. Intra-operatively, it was found that the stone was very much increased in size leading to a giant sialolith of $50 \times 12 \mathrm{~mm}$ size (Figure 2). Postoperative period was uneventful and the patient has been asymptomatic for the past one year.

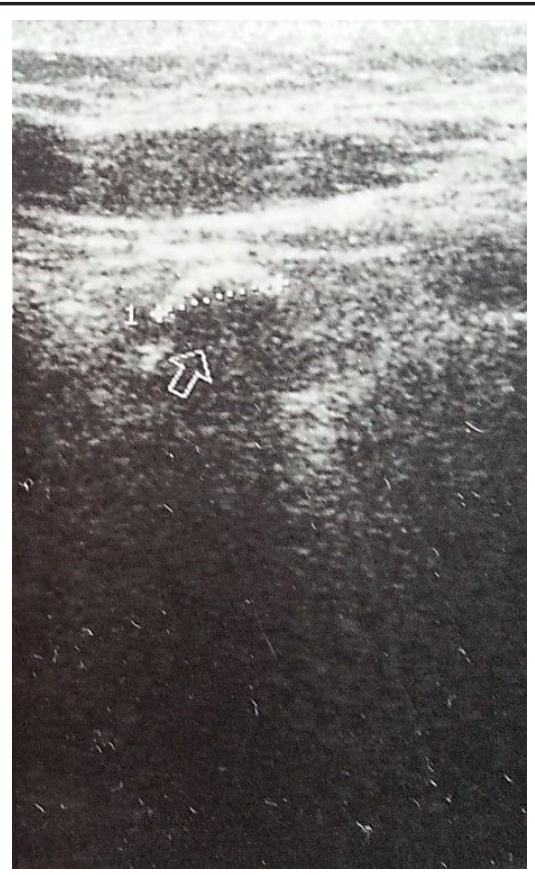

Figure 1. USG right submandibular region revealing a calcified stone of size $2.5 \times 1 \mathrm{~cm}$ in the submandibular duct.

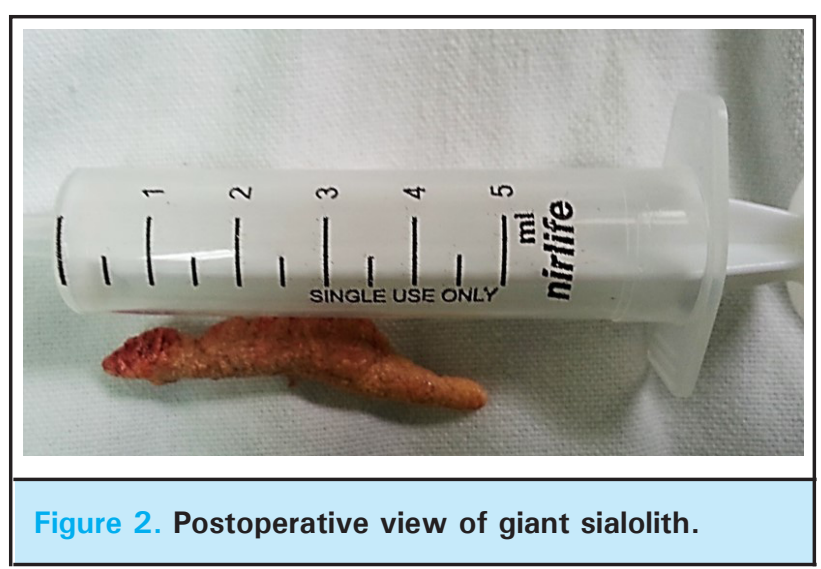

\section{DISCUSSION}

Salivary calculi are usually small and measure from 1 $\mathrm{mm}$ to less than $1 \mathrm{~cm}$. They rarely measure more than $1.5 \mathrm{~cm} .^{9,10}$ Bodner described sialoliths measuring $>15$ $\mathrm{mm}$ in any dimension or weighing $1 \mathrm{~g}$ as 'giant' whereas
Ledesma-Montes $\mathrm{C}$ et al classified sialoliths to be giant only if the size is $3.5 \mathrm{~cm}$ or larger. ${ }^{8,9}$ We propose, when the size of the sialolith is $5 \mathrm{~cm}$ or more it can be called as a 'Mega' sialolith as in our case.

Although the exact etiology is unknown, sialoliths are thought to occur as a result of deposition of mineral salts around an initial nidus consisting of salivary mucin, bacteria or desquamated epithelial cells. ${ }^{2}$ Most calculi occur in Wharton duct, whereas the rest are found at the ductal hilum or within the gland. ${ }^{11}$ Sialolithiasis of submandibular gland usually has an asymptomatic course. The symptoms begin whenever the lumen of Wharton duct is obstructed by a salivary calculus, with resultant accumulation of saliva causing pain and swelling of the involved gland during meals, because the stone usually does not block the flow of saliva completely. ${ }^{10}$ The stasis of saliva can lead to bacterial ascent into the parenchyma of the gland and therefore recurrent infections. Long-term obstruction of salivary flow and recurrent infections can lead to atrophy of the gland with resultant loss of secretory function and ultimately fibrosis.

Bimanual palpation of the floor of the mouth, in a posterior to anterior direction, reveals a palpable stone in a large number of cases of submandibular calculi. It is believed that a calculus enlarges at the rate of approximately 1 to $1.5 \mathrm{~mm}$ per year but in our case the calculus enlarged rapidly within 6 months to form a giant sialolith. ${ }^{7}$

Imaging studies like mandibular occlusal radiograph [best for radioopaque], sialography, ultrasound, computed tomography, scintigraphy and magnetic resonance sialography are available for diagnosing sialoliths. ${ }^{12,13}$ Ultrasound can demonstrate sialoliths with high accuracy and can correctly localize them anatomically. Sialendoscopy, which examines the ductal system completely, can be used for both diagnostic and treatment purposes and it was reported to be superior to plain radiograph or even to magnetic resonance imaging especially for small and more distally located stones. ${ }^{14-16}$ In our case ultrasound was done initially since it was readily available in outpatient basis to assess the size of the stone as well as to evaluate the gland parenchyma.

The primary objective of treatment of giant sialoliths is restoration of the normal salivary secretion. Various treatment options like intraoral removal of stone, interventional sialendoscopy, piezoelectric extracorporal shock wave lithotripsy, endoscopic intracorporeal shockwave lithotripsy and resection of the gland may be selected according to the size, number and location of the sialolith. ${ }^{2,7,9}$ Small sialoliths can be removed through the duct orifice using bimanual palpation or 
conservative management may be attempted with local heat, massage and sialogogues. ${ }^{2}$ For Larger or proximally located sialoliths in the duct a simple surgical release can be performed by an incision in the floor of the mouth. Incising the duct transorally can assist in removing more posteriorly located stones and care has to be taken to avoid damage to the lingual nerve. Submandibular gland resection is indicated when the gland has been damaged by recurrent infection and fibrosis, or sialolith with substantial mass $12 \mathrm{~mm}$ or more) is located within the gland and intraoral surgical access is not possible. ${ }^{7}$
To conclude, sialoliths are common in the submandibular gland and can progress to giant forms even within months. Hence early intervention is recommended to preserve the function of salivary gland and to avoid potential complications.

\section{Conflict of Interest: None.}

Consent: JNMA Case Report Consent Form was signed by the patient and the original is attached with the patient chart.

\section{REFERENCES}

1. Alyas F, Lewis K,Williams M, Moody AB,Wong KT, Ahuja AT,et al. Diseases of the submandibular gland as demonstrated using high resolution ultrasound. Br J Radiol. 2005;78:362-9. [PubMed]

2. Austin T, Davis J, Chan T. Sialolithiasis of submandibular gland. J Emerg Med. 2004;26:221-3. [PubMed]

3. Levy DM, ReMine WH, Devine KD. Salivary gland calculi. Pain, swelling associated with eating. JAMA. 1962;181:1115-1119 [PubMed]

4. McKenna JP, Bostock DJ, McMenamin PG. Sialolithiasis. Am Fam Physician. 1987;36:119-25. [PubMed]

5. Perrotta RJ, Williams JR, Selfe RW. Simultaneous bilateral parotid and submandibular gland calculi. Arch Otolaryngology. 1978;104:469-76. [PubMed]

6. Pollack CV Jr, Severance HW Jr. Sialolithiasis: case studies and review. J Emerg Med. 1990;8:551-65. [PubMed]

7. Biddle RJ, Arora S. Giant Sialolith of the Submandibular Salivary Gland. Radiol Case Rep. 2015 Dec 7;3(2):101. [PubMed]

8. Bodner L. Giant salivary gland calculi: diagnostic imaging and surgical management. Oral Surg Oral Med Oral Pathol Oral Radiol Endod. 2002;94:320. [PubMed]

9. Ledesma-Montes C, Garces-Ortiz M, Salcido-Garcia JF, Hernandez-Flores F, Hernandez-Guerrero JC. Giant sialolith: Case report and review of the literature. J Oral Maxillofac Surg. 2007;65:128-130. [PubMed]
10. Sutay S, Erdag TK, Ikiz AO, Guneri EA. Large submandibular gland calculus with perforation of the floor of the mouth. Otolaryngol Head Neck Surg. 2003;128:587-588. [PubMed]

11. Goudot P, Mondie JM, Champroux T, Jouve C, Peri G. Cutaneous parotid fistula of calculous origin. Rev Stomatol Chir Maxillofac. 1986;87:257-9. [PubMed]

12. Lomas DJ, Carroll NR, Johnson G, Antoun NM, Freer CE. MR sialography: work in progress. Radiology. 1996;200:129133. [PubMed]

13. Fischbach R, Kugel H, Ernst S, Schröder U, Brochhagen HG, Jungehülsing $M$, Heindel W. MR sialography: initial experience using a T2 weighted fast SE sequence. J Comput Assist Tomogr. 1997;21:826-830. [PubMed]

14. Konigsberger R, Feyh J, Goetz A, Kastenbauer E.Endoscopically controlled electrohydraulic intracorporeal shock wave lithotripsy (EISL) of salivary stones. J Otolaryngol. 1993;22:12-13. [PubMed]

15. Arzoz E, Santiago A, Esnal F, Palomero R. Endoscopic intracorporeal lithotripsy for sialolithiasis. J Oral Maxillofac Surg. 1996;54:847-852. [PubMed]

16. Yu CQ, Yang C, Zheng LY, Wu DM, Zhang J, Yun B. Selective management of obstructive submandibular sialadenitis. Br J Oral Maxillofac Surg. 2008;46:46-49. [PubMed] 